\title{
Memórias do teatro, para a História
}

\section{Miguel Falcão}

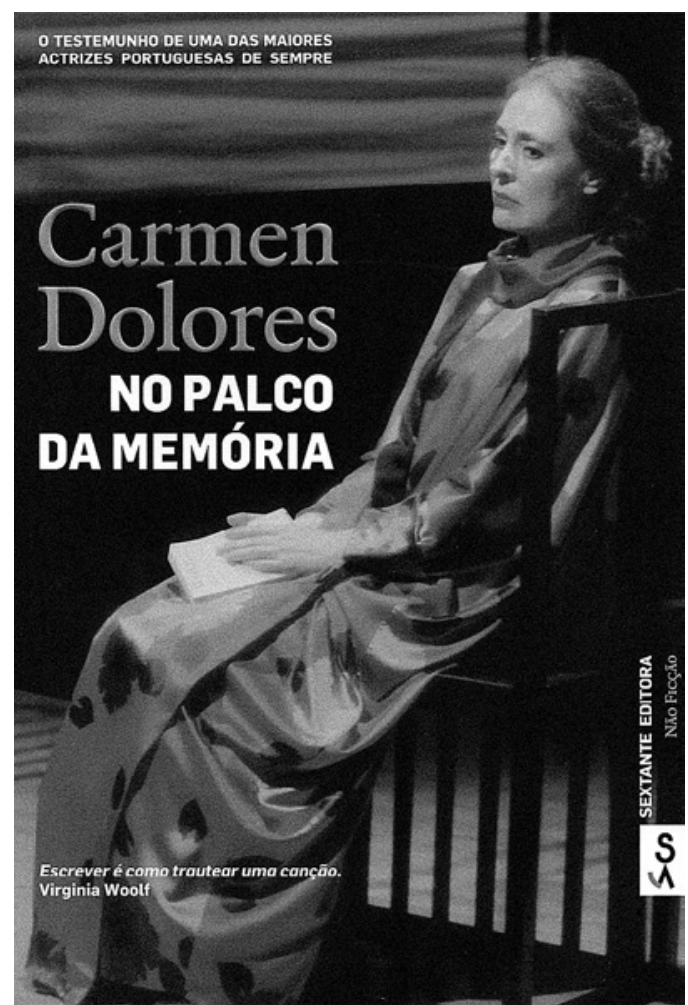

Carmen Dolores, No palco da memória, S.l. [Lisboa], Sextante Editora, 2013, pp. 272 pp.

Nas últimas décadas, sobretudo nas três últimas, o panorama editorial português, na especifica área do teatro, tem registado, ainda que timidamente, um interesse crescente pela fixação em livro das histórias de colectivos artísticos, desse modo preservando no papel - e, por vezes, também noutros suportes - o que, nas artes performativas é, por natureza, efémero.

A Comuna - Teatro de Pesquisa (CTP, 1997), o Trigo Limpo - Teatro ACERT (TLTA, 2001), o Teatro da Cornucópia (TC, 2002) e o Teatro 0 Bando (Campo das Letras, 2005), são apenas alguns exemplos de companhias que promoveram este tipo de iniciativas, a que acrescem aquelas que cativaram a atenção de estudiosos, como a Companhia Rey Colaço - Robles Monteiro (Museu Nacional do Teatro, 1989), por Vitor Pavão dos Santos, ou o Teatro Moderno de Lisboa (Caminho, 2009), por Tito Lívio, bem como os resultados de estudos académicos que vêm sendo concluídos e, nalguns casos, também publicados, como, entre outros, o que Rui Pina Coelho dedicou à Casa da Comédia (INCM, 2009). Na mesma linha, e com equivalente relevo, têm sido publicadas biografias de destacadas figuras do teatro, com enfoque nos actores e nos encenadores, como Raul Solnado (Difusão Cultural, 1991; Círculo de Leitores, 1992; e Oficina do Livro, 2003 e 2009), por Leonor Xavier; José Viana (Câmara Municipal de Oeiras, 1997), por Lauro António; Luís Miquel Cintra (Cotovia, 2001) e Joaquim Benite (Companhia de Teatro de Almada, 2013), por Maria Helena Serôdio; Ruy de Carvalho (Dom Quixote, 2004), por Palmira Correia; ou, entre outros, Ivone Silva e Maria Dulce (Sete Caminhos, 2006), Beatriz Costa (Sete Caminhos, 2008), Vitor de Sousa (Fonte da Palavra, 2012), Ângela Pinto (Apenas Livros, 2012) ou João D'Ávila (Fonte da Palavra, 2013), por Luciano Reis. Vale a pena realçar mais dois títulos em que a parte textual se encontra complementada por uma importante presença iconográfica: Amélia Rey Colaço, por Júlio de Barros, e Vasco Santana, por Luís Trindade (ambos editados na Colecção Fotobiografias do Século XX dirigida por Joaquim Vieira, Círculo de Leitores, 2009)

Menos comum tem sido a publicação de livros de memórias por artistas de teatro, embora não devamos esquecer os testemunhos significativos deixados por vultos como Lucinda Simões (Fluminense, 1922), Adelina Abranches (Empresa Nacional de Publicidade, 1947), Maria Matos (Livraria Popular de Francisco Franco, 1955) ou, entre outros, num tempo mais próximo, Costa Ferreira (INCM, 1985) e Luiz Francisco Rebello (Parceria A. M. Pereira, 2004). No palco da memória surge nesta linhagem. Na sequência de Retrato inacabado: memórias (0 Jornal, 1984), Carmen Dolores (n. 1924) retoma, nesta obra, um olhar pessoal pela sua própria história de vida e, em particular, pelo seu percursode actriz, profissão que, após a publicação do primeiro livro, continuou a exercer activamente por mais duas décadas. A autora não opta, todavia, por uma narrativa contínua e cronológica, preferindo registar - em cerca de sete dezenas de textos autónomos, organizados em nove partes principais - "o que [lhe] ia acontecendo, o que ia observando, o que [lhe] 
despertava mais interesse", conforme expressa na introdução a que dá o título "Escrever é bom!" (pp. 11-12).

Embora a ligação da autora ao teatro atravesse toda a obra, as quatro primeiras partes - "De mim" (pp. 13-28), "Encontros e desencontros" (pp. 29-52), "Da observação" (pp. 53-59) e "Da imaginação" (pp. 61-93) - centram-se privilegiadamente, e por esta ordem, nas memórias de familia; no seu relacionamento, mais próximo ou mais distante, com personalidades que admira (das letras, como Alexandre O'Neill, David Mourão-Ferreira, José Gomes Ferreira e Natércia Freire; das artes plásticas, como Maria Helena Vieira da Silva; da música, como Zeca Afonso; e do teatro, como o actor e encenador Francisco Ribeiro e o dramaturgo e crítico Mário Sério); em episódios do quotidiano, por vezes inusitados, que suscitaram a sua reflexão; e em histórias que parecem ter sido ficcionadas a partir de situações e pessoas que mereceram a sua atenção. Entre elas, porém, Carmen Dolores revela a sua estreia como espectadora no "galinheiro" do Teatro Nacional D. Maria II donde, aos dezasseis anos, assistiu a Frei Luís de Sousa, de Almeida Garrett, com Palmira Bastos e Maria Lalande nos papéis principais, peça que, anos mais tarde, ela própria representaria naquele mesmo Teatro, primeiro como "Maria de Noronha" e, depois, como "Madalena de Vilhena".

As cinco partes seguintes são mais especificamente dedicadas à sua carreira de actriz. Em "Da profissão" (pp. 95-118), tece uma série de reflexões sobre o teatro, 0 actor, os momentos de "nervos" e "expectativa" que antecedem a entrada em cena, as distinções e os prémios que the foram atribuidos, a sua relação com o público e com os artistas que considera "grandes", entre os quais, os actores Nascimento Fernandes, Álvaro Benamor, Assis Pacheco, João Villaret, Alves da Cunha e António Silva, e as actrizes Amélia Rey Colaço, Maria Matos, Brunilde Júdice e Lucília Simões. 0 texto que encerra este conjunto, "Os papéis que não fiz", como "Margarida Gauthier" de $A$ dama das camélias, de Alexandre Dumas, e "Hedda Gabler" da peça homónima de Henrik Ibsen, faz a ponte com a parte seguinte, "De personagem em personagem" (pp. 119-170), a mais extensa. Aqui, detém-se, um a um, nos papéis - em todos os casos como protagonista feminina - que interpretou em onze espectáculos que quis destacar a partir de textos de Arbuzov, Tchekov, Strindberg, Pirandello, Beckett, Ibsen, Tennessee Williams e, entre outros, Michae Frayn, autor de Copenhaga, o espectáculo levado à cena no Teatro Aberto, com encenação de João Lourenço, e com o qual fez a sua despedida de cena em 2005.
Neste livro focado principalmente no palco, a autora não esquece outras facetas do seu percurso de actriz e de artista comprometida com os colegas e o público, pelo que, na parte "E ainda o cinema, a televisão, a rádio, os admiradores e a Casa do Artista" (pp. 171-198), integra uma miscelânea de textos sobre os tópicos que o próprio título anuncia. Este conjunto, em que o leitor encontra descrições apaixonadas dos ambientes de gravação (em cinema, televisão e rádio), é complementado com a transcrição de excertos de cartas, enviadas por quem acompanhou a sua carreira e apreciou o seu trabalho, e rematado com um breve historial da criação da "casa para os artistas desamparados" (p. 197) e da sua colaboração nesse projeto.

A anteceder a "Pequena biografia" que encerra o livro (pp. 255-269), organizada por períodos temporais e diferentemente de todos os outros textos - redigida na terceira pessoa, a autora integra duas partes dedicadas ao que os outros escreveram sobre si. Em "O que disseram de mim" (pp. 199-243), reúne algumas das críticas que considerou mais "gratas" e "determinantes", incluindo a reprodução de recortes de jornais, tendo reservado, para "E ainda palavras que não posso esquecer..." (pp. 245254), a revelação de textos, na maioria inéditos, que the foram dedicados por amigos, entre os quais Jorge Listopad, um dos encenadores com quem mais trabalhou e que sobre si escreveu, em Abril de 1991, na revista Palco:

"Quando me dá o prazer de trabalhar comigo, é o meu Natal. Renasço. (...) Se eu tivesse fome, podia alimentar-me todos os dias das palavras dos textos teatrais, que Carmen transforma em canto, alegre ou triste, triste como as nénias, alegre como eu serei amanhã" (p. 247).

No palco da memória - que Carmen Dolores dedica a Victor, seu "companheiro exemplar" e grande apreciador de teatro, falecido no decurso da preparação da obra - é uma publicação cuidada e de grande qualidade gráfica, da responsabilidade do ateliê Henrique CayatteDesign, com Susana Cruz, em que sobressai uma escrita cativante e envolvente, enriquecida com perto de trinta fotografias de cena. Trata-se de um livro que merece atenção, e não somente da parte dos admiradores da actriz: nele, são apresentados testemunhos que, embora pessoais, lançam pistas para novos ou mais completos olhares sobre artistas, obras e situações, constituindo um contributo importante para esse empreendimento em permanente elaboração que é a História do Teatro em Portugal. 